\title{
Smart Aptamer and Protein Functionalized Poly( $N$-isopropylacryl- amide) Materials for Selective Extraction of Riboflavin in Beer
}

\author{
Xinxin Wang, Longqing NiU, Xinyi YAng, Jiao Zheng, Xinghu Jı, and Zhike $\mathrm{HE}^{\dagger}$ \\ Key Laboratory of Analytical Chemistry for Biology and Medicine (Ministry of Education), College of Chemistry \\ and Molecular Sciences, Wuhan University, Wuhan 430072, China
}

\begin{abstract}
Materials which can be combined with riboflavin specifically based on smart functionalized polymer were studied for their ability to selectively extract riboflavin from beer. The extraction was done directly by the affinity interaction of riboflavin with the riboflavin aptamer or riboflavin binding protein (RBP). Poly $(N$-isopropylacrylamide) (PNIPAAm) was introduced as a carrier and modified with riboflavin aptamer and RBP, respectively, in order to be conducive to the separation of riboflavin originally present in the beer. The produced complexes can be readily separated from the aqueous phase and benefited from the temperature sensitive property of this smart polymer. The study showed riboflavin could be selectively removed from a standard solution and beer satisfactorily and the nonspecific binding was almost negligible. In the manufacturing process of beer, this separation method has a great potential to prolong the storage period of beer and improve the quality of the products.
\end{abstract}

Keywords Riboflavin, beer, smart polymer, aptamer, riboflavin binding protein

(Received January 22, 2018; Accepted March 1, 2018; Published July 10, 2018)

\section{Introduction}

Riboflavin is an essential vitamin in human nutrition occurring in a wide variety of food products, and it is produced biotechnologically and used in vitamin enriched food and food supplements. ${ }^{1-4} \quad$ Additionally, riboflavin is an important biological redox cofactor that can act as the universal precursor of the flavin adenine dinucleotide and coenzyme flavin mononucleotide. ${ }^{5}$ In view of this, riboflavin is indispensable for the activity of a wide variety of metabolic enzymes in microbes, plants and animals, and it is very important for human and animal health. ${ }^{6}$

However, in the beer manufacturing industry, the effect of riboflavin is not as positive as it is in the human body. Beer is a fermented alcoholic beverage brewed from malt and flavored with hops. ${ }^{7,8}$ Owing to its contribution to bitterness, the hop plant is regarded as an essential raw material in the brewing process that can lead to a balanced and pleasant taste of beer products. ${ }^{9}$ As a result, the hop plant has been widely accepted among all the herbs that have been used in beer. ${ }^{10}$ Substances in hops can produce iso- $\alpha$-acids, which are intensely bitter. ${ }^{11}$ When exposed to visible light, especially in the $350-500 \mathrm{~nm}$ range, with the intervention of a photosensitizer such as riboflavin, the quality of beer will be affected. ${ }^{12,13}$ Because light of this wavelength can trigger the photodegradation of iso- $\alpha$ acids, this results in the formation of the volatile compound 3-methyl-2-butene-1-thiol (MBT), which has a foul smell. This phenomenon is generally referred to as "lightstruck flavor" (LSF). ${ }^{14}$ Experiments have proved that the concentration of

$\dagger$ To whom correspondence should be addressed.

E-mail: zhkhe@whu.edu.cn
MBT increases linearly with an increase in riboflavin concentration..$^{15}$ Accordingly, the concentration of riboflavin in beer is a major factor for assessing flavor stability. ${ }^{16,17}$ Riboflavin removal has been proposed as a strategy for controlling sunstruck flavor formation. ${ }^{18}$ Manesiotis et al. reported a kind of water-compatible imprinted polymers for selective depletion of riboflavin from beverages. The hydrophilic polymers, when subjected to beer, showed a maximum removal of $86 \% .^{19}$

In this study, the riboflavin aptamer and riboflavin binding protein (RBP) were introduced respectively as captures that can bind specifically to riboflavin. Aptamers, short single-stranded oligonucleotides with recognition abilities for specific targets, have become a notable class of targeting ligand biomarker with high therapeutic potential. ${ }^{20-23}$ Aptamers can fold into unique tertiary structures with a combination of complementary molecular shapes, hydrogen bonding, or stacking interactions that recognize specific targets ranging from small molecules and proteins to intact cells. ${ }^{23}$ It is well known that AP sites are formed by spontaneous hydrolysis of an $N$-glycosidic bonder by the removal of damaged or inappropriate bases by $N$ glycosylases. $^{24}$ Sankaran et al. incorporated such lesion sites into the duplex, for which a normal DNA is complementarily hybridized with an AP-site-containing DNA. ${ }^{25}$ A class of DNA aptamers were built, in which an AP site in the duplex was utilized as an active cavity for riboflavin recognition. ${ }^{24,26}$ In addition to the riboflavin aptamers, we also introduced RBPriboflavin combinations to realize the extraction of riboflavin in beer. RBP, a globular monomeric phosphorylated glycoprotein isolated from hens' egg white, is responsible for specifically binding and transporting riboflavin to the embryo, supporting its growth and development until hatching. ${ }^{27,28}$ Riboflavin and RBP can be strongly combined at the ratio of $1: 1$ and the dissociation constant is approximately $1.3 \times 10^{-9} \mathrm{M}^{29}$ 

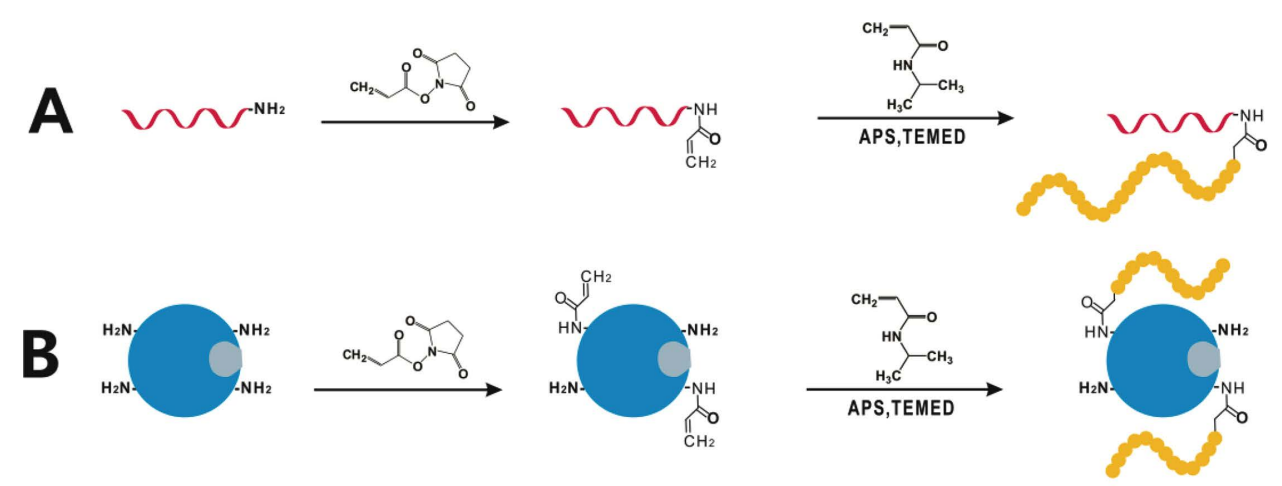

Fig. 1 Schematic illustration of principle for the preparation of smart functionalized polymers: (A) PNIPAAm- $c o$-RAP and (B) PNIPAAm-co-RBP.

Riboflavin binding proteins could form the combination to selectively extract the riboflavin. This might be conducive to limiting sunstruck flavor formation in beer.

In order to separate the riboflavin from beer, and thus prolonging the storage time of products, thermosensitive polymer poly( $N$-isopropylacrylamide) (PNIPAAm) was utilized as a coupling object with the riboflavin aptamers (PNIPAAmco-RAP) and RBP (PNIPAAm-co-RBP), respectively. ${ }^{30-32}$ Thermosensitive polymers are soluble in a certain solvent as homogenous solutions at low temperatures but a phase separation is induced by surpassing a certain temperature threshold, which is defined as the lower critical solution temperature (LCST). ${ }^{33}$ In view of the above principle, separation of riboflavin can achieve good effects by changing the temperature in a homogeneous solution. By integrating the advantages of the high affinity of the riboflavin aptamer and RBP with riboflavin, the two kinds of smart functionalized polymers may open a new path to extending the shelf life of beer.

\section{Experimental}

\section{Materials and reagents}

$N$-Isopropylacrylamide (NIP), acrylic acid $N$-hydroxysuccinimide ester (NAS), ammonium persulfate (APS), $N, N, N, N-$ tetramethylethylenediamine (TEMED), tris(hydroxymethyl) aminomethane hydrochloride (Tris), sodium phosphate dibasic, sodium phosphate monobasic dihydrate, sodium chloride, ethylenediaminetetraacetic acid disodium salt (EDTA) and RBP were obtained from Sigma-Aldrich (USA). All the above reagents were of analytical-reagent grade or higher. Hydrochloric acid was purchased from Sinopharm Chemical Reagent Co., Ltd. Harbin beer (sample 1) was purchased from Harbin Beer Co., Ltd. Snow beer (sample 2) was purchased from China Resources Breweries Co., Ltd. Pineapple beer (sample 3) and Blue Ribbon beer (sample 4) were purchased from Blue Ribbon Co., Ltd. All oligonucleotides with different sequences were synthesized and purification was performed by high-performance liquid chromatography (HPLC) by Sangon Biotechnology Co., Ltd. (Shanghai, China). The sequences of the oligonucleotides are as follows:

\section{Aptamer A: 5'-NH2 C6-GTG TGC GTT GCT CTG GAC} GCA GA-3'
Aptamer B: 5'-TCT GCG TCC AG-C3 Spacer-GCA ACG CAC AC-3'

FAM-DNA: 5'-FAM-TCT GCG TCC AGA GCA ACG CAC AC- $3^{\prime}$

DNA 1: 5'-NH2 C6-CTA TTG CAT CTT CCG TTA CA A CT-3'

\section{DNA 2: 5'-AGT TGT AAC GGA AGA TGC AAT AG-3'}

Ultrapure water was obtained by a Milli-Q academic purification set (Millipore, USA). Fluorometric spectra were obtained with an RF-5301PC spectrophotometer (Shimadzu, Japan) equipped with a $150-\mathrm{W}$ xenon lamp (Ushio Inc, Japan). ZF-20D ultraviolet analyzer produced by Gucun Photoelectric Instrument Factory (Shanghai, China) was used in this study.

\section{Determination of the concentration of riboflavin in beer}

First, $3.8 \mathrm{mg}$ riboflavin was dissolved in $100 \mathrm{~mL}$ Tris- $\mathrm{HCl}$ buffer solution (Tris $10 \mathrm{mM}, \mathrm{NaCl} 150 \mathrm{mM}$, EDTA $1 \mathrm{mM}$ ) as a standard solution and stored at $4{ }^{\circ} \mathrm{C}$ away from light before use. In order to determine the amount of riboflavin in beer, the fluorescence intensities of different concentrations $(0.10,0.50$, $1.0,2.0,3.0,4.0 \mu \mathrm{M})$ of riboflavin were detected to draw a standard curve. Afterwards, the fluorescence intensity of the same volume of Harbin beer sample was recorded to calculate the concentration of riboflavin in the sample. Subsequently, standard addition experiments of different concentrations $(0,3.0,6.0,9.0,12 \mu \mathrm{M})$ of riboflavin was conducted to further prove the amount of riboflavin in the beer sample.

Investigation of the binding effect between aptamers and riboflavin

Firstly, different concentrations of aptamer A were mixed with the same concentration of aptamer B, respectively, for $30 \mathrm{~min}$ to form DNA duplexes. Next, $1.0 \mu \mathrm{M}$ riboflavin was added into the reaction products for $1 \mathrm{~h}$. Later, the fluorescence intensities of riboflavin before and after being trapped were recorded.

\section{Preparation and investigation of PNIPAAm-co-RAP}

As shown in Fig. 1A, PNIPAAm-co-RAP was prepared by utilizing NAS as a coupling reagent. Active ester groups can react with amino groups modified on DNA and the $\mathrm{C}=\mathrm{C}$ of NAS can polymerize with the C=C of NIP. Briefly, $230 \mu \mathrm{L}$ of $100 \mu \mathrm{M}$ aptamer A was coupled with $200 \mu \mathrm{L}$ NAS in DMSO of $2.0 \mathrm{mg}$ $\mathrm{mL}^{-1}$, and incubated at $37^{\circ} \mathrm{C}$ under stirring for $1 \mathrm{~h}$. Afterwards, 
$60 \mathrm{mg}$ NIP, $10 \mathrm{mg}$ APS and $10 \mu \mathrm{L}$ TEMED were added into the coupling product in $5 \mathrm{~mL}$ of PBS buffer solution $\left(\mathrm{Na}_{2} \mathrm{HPO}_{4}\right.$ $\left.10 \mathrm{mM}, \mathrm{NaH}_{2} \mathrm{PO}_{4} 10 \mathrm{mM}, \mathrm{NaCl} 15 \mathrm{mM}, \mathrm{pH} 7.4\right)$. After polymerization for $2 \mathrm{~h}$ by continuous shaking at $25^{\circ} \mathrm{C}$, PNIPAAm-co-RAP was precipitated at $37^{\circ} \mathrm{C}$ for $5 \mathrm{~min}$ and separated from unreacted monomers, aptamer $\mathrm{A}$ and small molecule impurities by centrifugation for $5 \mathrm{~min}$ at $37^{\circ} \mathrm{C}$ $(8000 \mathrm{rpm})$ and then resolved in $5 \mathrm{~mL}$ of cold PBS buffer solution. The purification cycle was replicated three times. The last time, PNIPAAm-co-RAP was resuspended in $500 \mu \mathrm{L}$ of PBS buffer solution and stored at $4{ }^{\circ} \mathrm{C}$ before use.

FAM-DNA, which could react with aptamer A according to the strict complementary nature of the base pairs, was utilized to determine the concentration of aptamer A in PNIPAAm-co-RAP of the final product. Firstly, different concentrations $(0.010$, $0.10,0.50,1.0,2.0,4.0 \mu \mathrm{M})$ of FAM-DNA were added into $30 \mu \mathrm{L}$ PNIPAAm-co-RAP solutions. The reaction volume was $300 \mu \mathrm{L}$. Next, the mixtures were shaken at $25^{\circ} \mathrm{C}$ for $30 \mathrm{~min}$ to form DNA double stranded structures. The fluorescence signal of each product was individually analyzed and the intensity was recorded. Simultaneously, the fluorescence intensities of different concentrations $(0.10,0.50,0.80,1.0,1.5 \mu \mathrm{M})$ of FAMDNA were detected to draw a standard curve. Afterwards, the concentration of aptamer A in PNIPAAm-co-RAP was calculated according to the maximum fluorescence intensity and the standard curve.

\section{Preparation and investigation of PNIPAAm-co-RBP}

As shown in Fig. 1B, PNIPAAm-co-RBP was also prepared by utilizing NAS as a coupling reagent. Active ester groups can react with amino groups of $\mathrm{RBP}$ and the $\mathrm{C}=\mathrm{C}$ of NAS can polymerize with the $\mathrm{C}=\mathrm{C}$ of NIP. Briefly, $200 \mu \mathrm{L}$ of $2.0 \mathrm{mg}$ $\mathrm{mL}^{-1} \mathrm{RBP}$ was coupled with $100 \mu \mathrm{L}$ NAS in DMSO of $10 \mathrm{mg}$ $\mathrm{mL}^{-1}$, and incubated at $37^{\circ} \mathrm{C}$ under stirring for $1 \mathrm{~h}$. Afterwards, $40 \mathrm{mg}$ NIP, $10 \mathrm{mg}$ APS and $10 \mu \mathrm{L}$ TEMED were added into the coupling product in $3 \mathrm{~mL}$ of PBS buffer solution. After polymerization for $2 \mathrm{~h}$ by continuous shaking at $25^{\circ} \mathrm{C}$, PNIPAAm-co-RBP was precipitated at $37^{\circ} \mathrm{C}$ for $5 \mathrm{~min}$ and separated from unreacted monomers, RBP and small molecule impurities by centrifugation for $5 \mathrm{~min}$ at $37^{\circ} \mathrm{C}(8000 \mathrm{rpm})$ and then resolved in $3 \mathrm{~mL}$ of cold PBS buffer solution. The purification cycle was replicated three times. Later, PNIPAAmco-RBP was resuspended in $3 \mathrm{~mL}$ of PBS buffer solution and stored at $4^{\circ} \mathrm{C}$ before use.

RBP has intrinsic fluorescence, which could make it very useful for determining the amount of RBP coupled with PNIPAAm in the final product. Firstly, the fluorescence response of different concentrations $(0.50,1.0,3.0,5.0,7.0 \mu \mathrm{M})$ of RBP was detected to draw a standard curve. Later, the fluorescence intensity of PNIPAAm-co-RBP was detected to calculate the concentration of RBP in this biomaterial.

Procedure of PNIPAAm-co-RAP applied in the extraction of riboflavin

Firstly, PNIPAAm-co-RAP condensed to different concentrations benefited from the temperature sensitive property of the material. Different volumes of PNIPAAm-co-RAP were precipitated at $37^{\circ} \mathrm{C}$ for $5 \mathrm{~min}$ and centrifuged for $3 \mathrm{~min}$ at $37^{\circ} \mathrm{C}$ (13000 rpm) and then resolved in $98 \mu \mathrm{L}$ of cold PBS buffer. Next, as shown in Fig. 2A, the same concentration of aptamer B as that of aptamer A in PNIPAAm-co-RAP and $1.0 \mu \mathrm{M}$ standard solution were added respectively and reacted at $25^{\circ} \mathrm{C}$ for $4 \mathrm{~h}$ to form DNA duplex aptamers and trapped the target. Later, products were precipitated at $37^{\circ} \mathrm{C}$ for $5 \mathrm{~min}$ and centrifuged for $3 \mathrm{~min}$ at $37^{\circ} \mathrm{C}(13000 \mathrm{rpm})$. The supernatants were collected

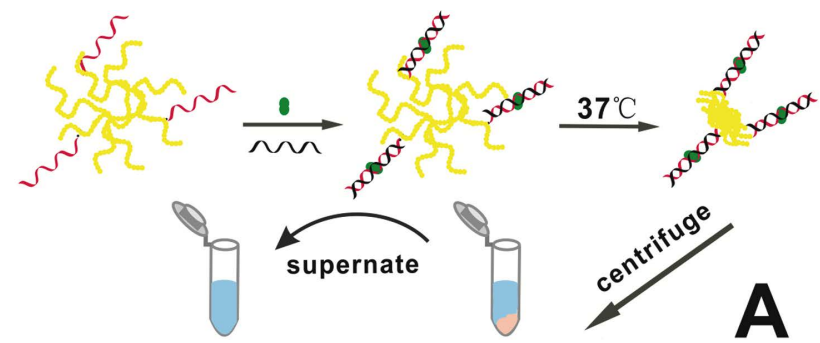

Polymer W AptamerA Riboflavin ఋ AptamerB

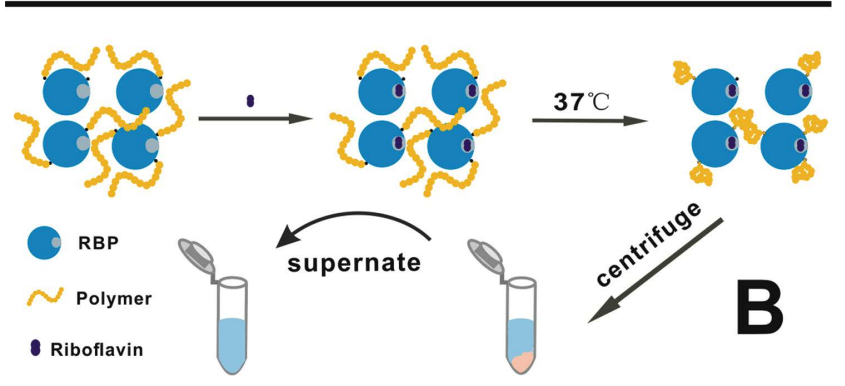

Fig. 2 Schematic illustration of principle for the extraction of riboflavin by (A) PNIPAAm- $c o$-RAP and (B) PNIPAAm- $c o$-RBP.

and the fluorescence intensities were recorded to determine the concentrations of riboflavin remaining in the samples.

In order to verify that the extraction of the target was based on the specific binding between captures and target rather than nonspecific adsorption, the same concentration of material coupled with DNA 1 (Supporting Information 1) was utilized in the experiments. The DNA duplex in this experiment was formed by DNA 1 and DNA 2. The procedure for riboflavin extraction was similar to that for PNIPAAm-co-RAP.

\section{Procedure of PNIPAAm-co-RBP applied in the extraction of riboflavin}

Similarly, different volumes of PNIPAAm-co-RBP were precipitated at $37^{\circ} \mathrm{C}$ for $5 \mathrm{~min}$ and centrifuged for $3 \mathrm{~min}$ at $37^{\circ} \mathrm{C}$ $(13000 \mathrm{rpm})$ and then resolved in $99 \mu \mathrm{L}$ of cold PBS buffer. Next, as shown in Fig. $2 \mathrm{~B}, 1.0 \mu \mathrm{M}$ standard solution was added into each solution above and reacted at $25^{\circ} \mathrm{C}$ for $4 \mathrm{~h}$. The processing method of the products was similar to that of PNIPAAm-co-RAP. The concentrations of riboflavin were determined by measuring the fluorescence intensities of the supernatants.

The material modified with streptavidin (SA) (Supporting Information 2) (PNIPAAm-co-SA) was synthesized and reacted with a standard solution with the same concentration as PNIPAAm-co-RBP to verify that the effects of nonspecific adsorption are negligible.

\section{Extraction of riboflavin in beer}

The optimum dosage of PNIPAAm-co-RAP in the above experimental scheme was incubated in Harbin beer (sample 1) at $25^{\circ} \mathrm{C}$ for $4 \mathrm{~h}$. And PNIPAAm-co-RBP in the above experimental scheme was incubated in Harbin beer (sample 1), Snow beer (sample 2), Pineapple beer (sample 3) and Blue Ribbon beer (sample 4 ) at $25^{\circ} \mathrm{C}$ for $4 \mathrm{~h}$. Later, products were precipitated at $37^{\circ} \mathrm{C}$ for $5 \mathrm{~min}$ and centrifuged for $3 \mathrm{~min}$ at $37^{\circ} \mathrm{C}$ (13000 rpm). The depletion of riboflavin was then measured by recording the fluorescence intensities of the supernatants. 

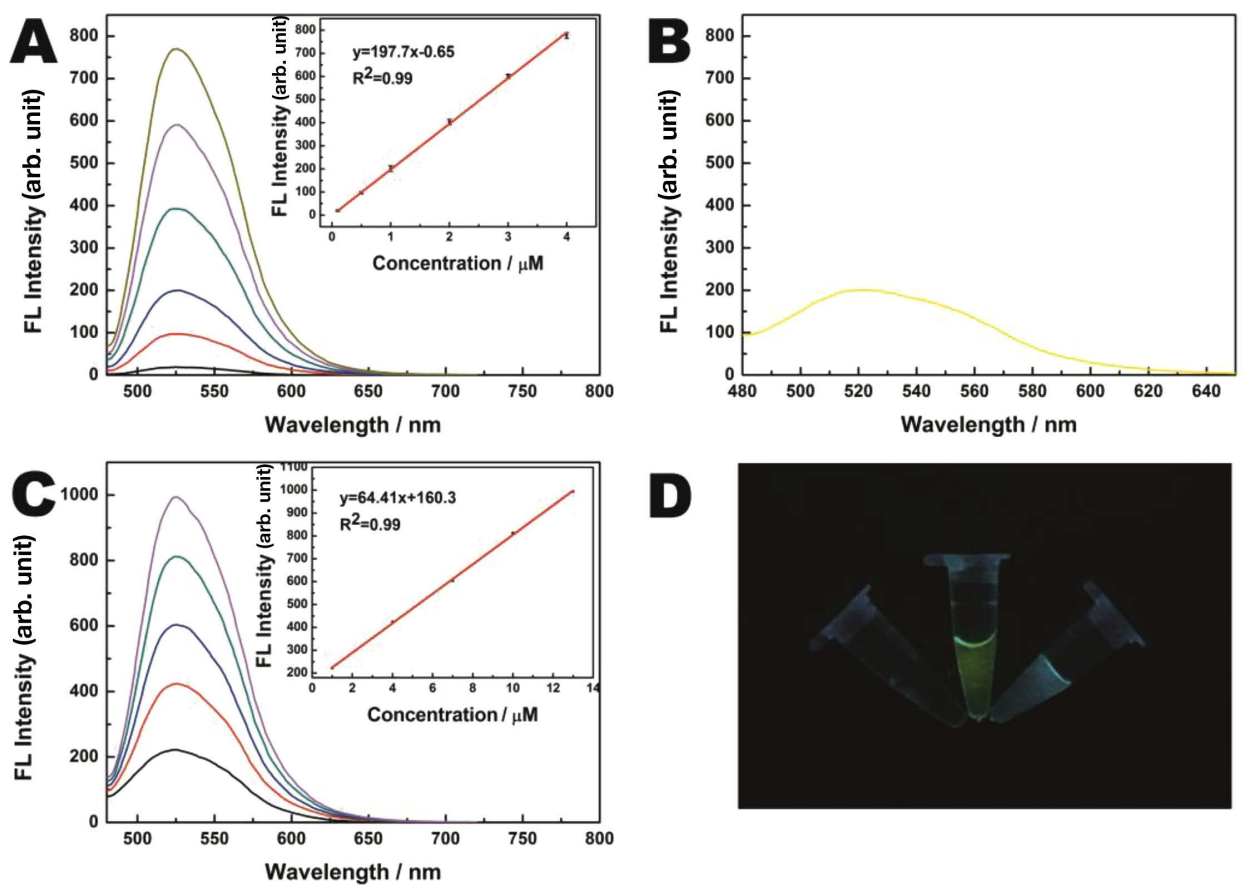

Fig. 3 The fluorescence responses of (A) different concentrations of riboflavin: 0.10, 0.50, 1.0, 2.0, 3.0, $4.0 \mu \mathrm{M}$ (from bottom to top). Inset: the linear relationship between the fluorescence intensity and the concentration of riboflavin, (B) Harbin beer and (C) different concentrations of riboflavin added to beer: $0.10,0.50,1.0,2.0,3.0,4.0 \mu \mathrm{M}$ (from bottom to top). Inset: the linear relationship between the fluorescence intensity and the concentration of riboflavin added. (D) The picture of buffer, riboflavin solution, and Harbin beer excited by an ultraviolet lamp.

\section{Results and Discussion}

\section{The concentration of riboflavin in beer}

As shown in Fig. 3A, the fluorescence intensity increased gradually with the increase of the concentration of riboflavin, and the regression equation was $y=197.7 x-0.65\left(R^{2}=0.99\right)$. The fluorescence intensity of riboflavin in Harbin beer was described in Fig. 3B. According to the standard curve of riboflavin in Fig. 3A, the concentration of riboflavin in Harbin beer was calculated and the result was $1.0 \mu \mathrm{M}$. The regression equation of standard addition experiment in Fig. 3C was $y=64.41 x+160.3 \quad\left(R^{2}=0.99\right)$, which further proved the reliability of the results. Figure $3 \mathrm{D}$ shows the difference between different samples (buffer, riboflavin solution and Harbin beer) excited by ultraviolet lamp, in which the difference between the different samples was obvious. The difference of the picture of fluorescence between Harbin beer and riboflavin solution was likely due to the influence of other substances in beer.

\section{The binding effect between aptamers and riboflavin}

Riboflavin DNA duplex aptamers utilized in this study contained AP sites. Riboflavin can bind selectively to the receptor nucleotide opposite an AP site in a DNA duplex through stacking interactions and hydrogen bonding. ${ }^{24}$ When the AP site was flanked by guanine bases, the fluorescence of riboflavin bound to the AP site was strongly quenched. ${ }^{25}$ This feature of the riboflavin-duplex interaction was of great practical value. In this study, riboflavin can be trapped and quenched by the riboflavin aptamer. Therefore, the alteration of fluorescence intensity of riboflavin can be utilized to analyze the binding effect between aptamers and riboflavin.

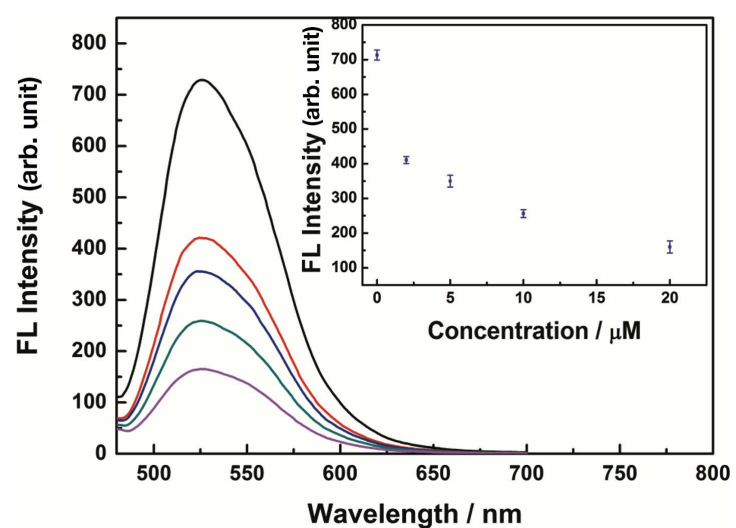

Fig. 4 The fluorescence responses of riboflavin in solutions after reaction.

As shown in Fig. 4, in the presence of DNA duplex aptamers, as mentioned earlier, riboflavin was trapped by aptamers and its fluorescence was quenched. With the increase of the concentration of DNA duplex aptamers, the effect was more obvious. The fluorescence intensity of riboflavin only remained $22.44 \%$ when the concentration of aptamers reached $20 \mu \mathrm{M}$. This proved the existence of interaction between riboflavin aptamer and riboflavin and this can be further applied.

\section{Preparation and investigation of PNIPAAm-co-RAP}

The fluorescence intensities of the complexes in the presence of various FAM-DNA concentrations are shown in Fig. 5A. Initially, the fluorescence intensity increased with increasing 

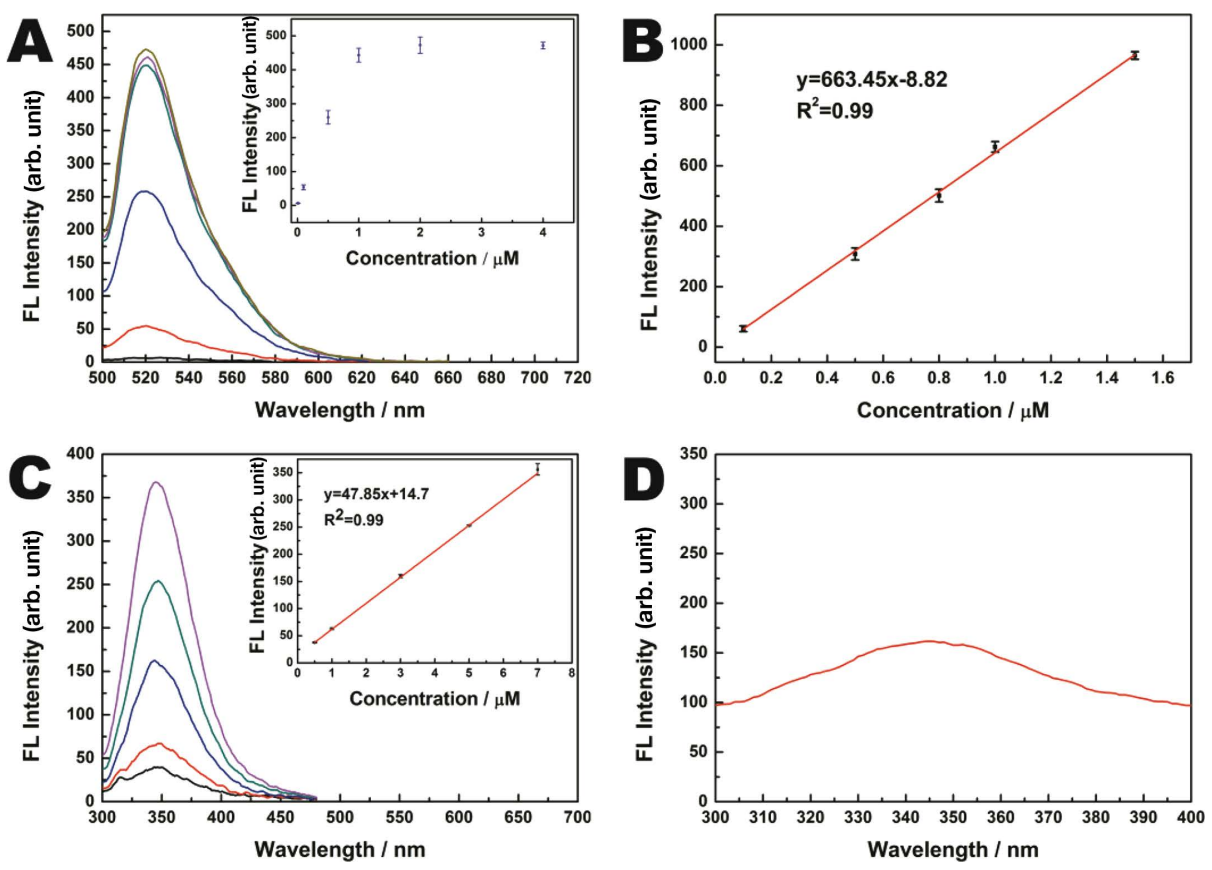

Fig. 5 (A) The fluorescence responses of the complexes formed by PNIPAAm-co-RAP and FAMDNA. (B) The linear relationship between the fluorescence intensity and the concentration of FAMDNA. (C) The fluorescence responses of different concentrations of RBP: 0.50, 1.0, 3.0, 5.0, 7.0 $\mu \mathrm{M}$ (from bottom to top). Inset: the linear relationship between the fluorescence intensity and the concentration of RBP. (D) The fluorescence response of PNIPAAm-co-RBP.

concentration of FAM-DNA. Nevertheless, when the concentration of FAM-DNA increased to a certain degree, $2.0 \mu \mathrm{M}$, which was close to the maximum amount with which aptamer A can combine, the fluorescence intensity reached a plateau. According to the regression equation $(y=663.45 x-8.82$ $\left.\left(R^{2}=0.99\right)\right)$ in Fig. 5B derived from the standard curve of FAM-DNA, the concentration of aptamer A coupled with PNIPAAm was $0.70 \mu \mathrm{M}$. The concentration of PNIPAAm-coRAP in the experiment was diluted 10 times, so the original concentration of PNIPAAm-co-RAP was recognized as $7.0 \mu \mathrm{M}$. And it was used to define the concentration of the material.

\section{Preparation and investigation of PNIPAAm-co-RBP}

The amount of RBP coupled with PNIPAAm in the final product can be determined by the intrinsic fluorescence of RBP. The fluorescence intensities of various RBP concentrations are shown in Fig. 5C and the regression equation is $y=47.85 x+14.7$ $\left(R^{2}=0.99\right)$. The fluorescence intensity of PNIPAAm-co-RBP is described in Fig. 5C. According to the regression equation above, the concentration of RBP coupled with PNIPAAm is calculated and the result is $3.0 \mu \mathrm{M}$. And it was used to define the concentration of the material.

Smart functionalized polymers applied in extraction of riboflavin Different concentrations of DNA duplex aptamers in PNIPAAm-co-RAP were incubated in $1.0 \mu \mathrm{M}$ standard solution and the results are shown in Fig. 6A. With the increase of the concentration of DNA duplex aptamers, the amount of riboflavin that remained in solution decreases gradually. In other words, the amount of riboflavin captured and extracted increases. The amount of riboflavin in the solution no longer decreased when the concentration of DNA duplex aptamers reached $21 \mu \mathrm{M}$. The capture capacity of this material was saturated with a $97 \%$ maximum riboflavin depletion. By contrast, as shown in
Fig. 6C(b), DNA duplex formed by DNA 1 and DNA 2 can extract only $13 \%$ riboflavin in the solution, which was much lower than that with DNA duplex aptamers. This showed that nonspecific adsorption in this experiment is weak.

Similarly, for PNIPAAm-co-RBP, different concentrations of this material were also incubated in $1.0 \mu \mathrm{M}$ standard solution. As shown in Fig. 6B, with the increase of the concentration of PNIPAAm-co-RBP, the amount of riboflavin that remained in solution decreased gradually, as more riboflavin was captured and extracted by this biomaterial. The extraction ability of PNIPAAm-co-RBP towards riboflavin reached an extreme value when the concentration of RBP reached $3.0 \mu \mathrm{M}$. Compared with PNIPAAm-co-RAP, PNIPAAm-co-RBP had a similar effect on riboflavin extraction with a nearly $97 \%$ maximum depletion. The nonspecific adsorption of proteins on the target was further investigated. As shown in Fig. 6D(b), PNIPAAmco-SA had almost no capture capability for riboflavin and can be ignored. This proved that the extraction of this material is specific to the target.

The results of smart functionalized polymers PNIPAAm-coRAP and PNIPAAm-co-RBP for selective extraction of riboflavin from beer are shown in Figs. $6 \mathrm{C}(\mathrm{c})$ and Fig. $6 \mathrm{D}(\mathrm{c})$, respectively. Compared with the fluorescence intensity of the original riboflavin in Harbin beer, PNIPAAm- $c o$-RAP extracted nearly $78 \%$ of the target from the samples and PNIPAAm-coRBP obtained a $90 \%$ riboflavin depletion. It can be noted that PNIPAAm-co-RBP had better ability to extract riboflavin than PNIPAAm-co-RAP.

In order to verify that this smart functionalized polymer, PNIPAAm-co-RBP, has good riboflavin extraction effectiveness for different beers, sample 2, sample 3 and sample 4 were introduced into the experiments and incubated with $3.0 \mu \mathrm{M}$ PNIPAAm-co-RBP. As shown in Fig. 7, this material has good effect on the extraction of riboflavin from different beer samples. 

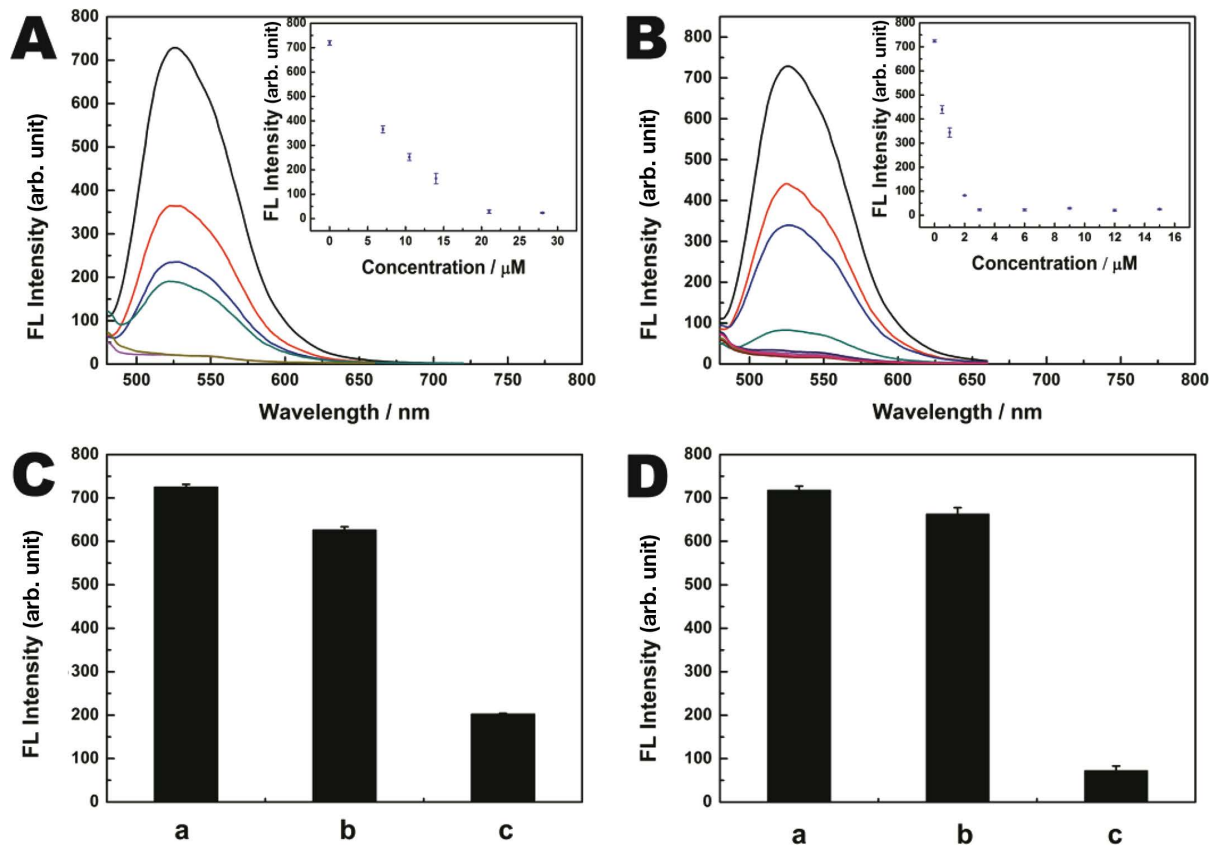

Fig. 6 The fluorescence responses of riboflavin remaining in solutions after extraction by (A) PNIPAAm-co-RAP and (B) PNIPAAm-co-RBP. (C) The fluorescence responses of (a) $1.0 \mu \mathrm{M}$ riboflavin, (b) riboflavin after extraction by PNIPAAm-co-DNA duplex (DNA 1 and DNA 2) and (c) riboflavin remaining in Harbin beer after extraction by PNIPAAm-co-RAP. (D) The fluorescence responses of (a) $1.0 \mu \mathrm{M}$ riboflavin, (b) riboflavin after extraction by PNIPAAm-co-SA and (c) riboflavin remaining in Harbin beer after extraction by PNIPAAm-co-RBP.

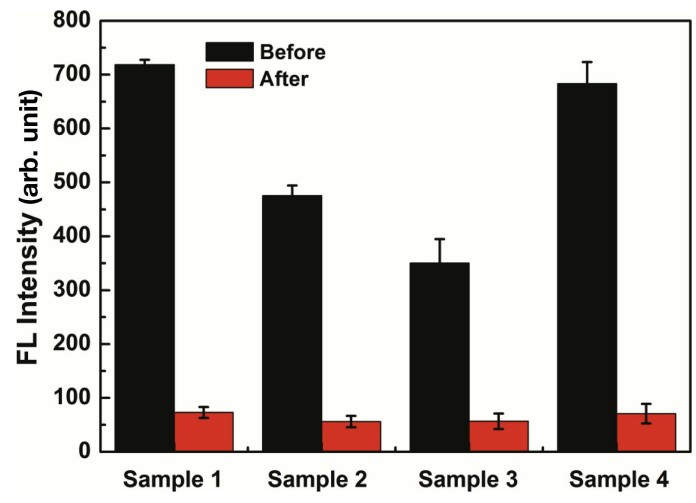

Fig. 7 The fluorescence responses of riboflavin remaining in different samples after extraction by PNIPAAm-co-RBP.

\section{Conclusions}

The existence of riboflavin could affect the shelf life of beer. In order to extract the riboflavin in beer and promote the development of storing technology in the beer industry, smart functionalized polymers PNIPAAm-co-RAP and PNIPAAm-coRBP were prepared with a simple method. Riboflavin aptamers and RBP can bind tightly to riboflavin, which ensured that the target in beer can be captured. In addition, these smart functionalized polymers displayed a controllable conformation change below or above its LCST, which was conducive to the separation of riboflavin in samples. Utilizing these advantages, the riboflavin in beer can be extracted with high depletion and the nonspecific binding was almost negligible. This kind of new material offers good prospects for prolonging the shelf life of beer and enhancing the quality of beer.

\section{Acknowledgements}

This research was supported by the National Natural Science Foundation of China (21475101, 21675119).

\section{Supporting Information}

Supporting Information includes preparation of PNIPAAm-coDNA 1 and PNIPAAm-co-SA, and the effect of incubation time on the fluorescence intensity of riboflavin after extraction. This material is available free of charge on the Web at http://www. jsac.or.jp/analsci/.

\section{References}

1. P. A. Tuan, J. K. Kim, S. Lee, S. C. Chae, and S. U. Park, J. Agric. Food. Chem., 2012, 60, 11980.

2. V. Paracchini, M. Petrillo, R. Reiting, A. Angers-Loustau, D. Wahler, A. Stolz, B. Schonig, A. Matthies, J. Bendiek, D. M. Meinel, S. Pecoraro, U. Busch, A. Patak, J. Kreysa, and L. Grohmann, Food Chem., 2017, 230, 681.

3. H. Wang, Q. Ma, Y. Wang, C. Wang, D. Qin, D. Shan, J. Chen, and X. Lu, Anal. Chim. Acta, 2017, 973, 34.

4. M. Voicescu, S. Ionescu, O. Craciunescu, R. Tatia, L. Moldovan, V. S. Teodorescu, and C. L. Nistor, New J. Chem., 2017, 41, 5533.

5. B. König, H. Gallmeier, and R. Reichenbach-Klinke, Chem. Commun., 2001, 2390.

6. R. W. Si, Y. Yang, Y. Y. Yu, S. Han, C. L. Zhang, D. Z. Sun, D. D. Zhai, X. Liu, and Y. C. Yong, Anal. Chem., 2016, 88, 11222 . 
7. D. Intelmann and T. Hofmann, J. Agric. Food. Chem., 2010, 58,5059 .

8. A. S. Araujo, L. L. da Rocha, D. M. Tomazela, A. C. Sawaya, R. R. Almeida, R. R. Catharino, and M. N. Eberlin, Analyst, 2005, 130, 884.

9. A. Heinlein, M. Metzger, H. Walles, and A. Buettner, Food Funct., 2014, 5, 2719.

10. A. Heinlein and A. Buettner, Food Funct., 2012, 3, 1059.

11. D. Intelmann, G. Haseleu, A. Dunkel, A. Lagemann, A. Stephan, and T. Hofmann, J. Agric. Food Chem., 2011, 59 , 1939.

12. I. Caballero, C. A. Blanco, and M. Porras, Trends Food Sci. Tech., 2012, 26, 21.

13. G. G. Stewart, J. Chem. Educ., 2004, 81, 963.

14. K. Huvaere, M. L. Andersen, M. Storme, J. Van Bocxlaer, L. H. Skibsted, and D. De Keukeleire, Photochem. Photobiol., 2006, 5, 961.

15. R. Pozdrik, F. A. Roddick, P. J. Rogers, and T. Nguyen, $J$. Agric. Food Chem., 2006, 54, 6123.

16. B. Hucker, L. Wakeling, and F. Vriesekoop, J. Agric. Food Chem., 2011, 59, 12278.

17. M. G. Duyvis, R. Hilhorst, C. Laane, D. J. Evans, and D. J. M. Schmedding, J. Agric. Food Chem., 2002, 50, 1548.

18. B. Hucker, F. Vriesekoop, A. Vriesekoop-Beswick, L. Wakeling, H. Vriesekoop-Beswick, and A. Hucker, J. Inst. Brewing, 2016, 122, 278.

19. P. Manesiotis, C. Borrelli, C. S. A. Aureliano, C. Svensson, and B. Sellergren, J. Mater. Chem., 2009, 19, 6185.
20. Y. Lao, K. K. L. Phua, and K. W. Leong, ACS Nano, 2015, 9, 2235

21. G. Zhu, G. Niu, and X. Chen, Bioconjugate Chem., 2015, 26, 2186.

22. W. Tan, M. J. Donovan, and J. Jiang, Chem. Rev., 2013, 113, 2842.

23. M. Famulok, J. S. Hartig, and G. Mayer, Chem. Rev., 2007, 107, 3715.

24. M. Li, Y. Sato, S. Nishizawa, T. Seino, K. Nakamura, and N. Teramae, J. Am. Chem. Soc., 2009, 131, 2448.

25. N. B. Sankaran, S. Nishizawa, T. Seino, K. Yoshimoto, and N. Teramae, Angew. Chem. Int. Ed., 2006, 45, 1563.

26. Y. Sato, Y. Zhang, S. Nishizawa, T. Seino, K. Nakamura, M. Li, and N. Teramae, Chemistry, 2012, 18, 12719.

27. K. Maehashi, M. Matano, M. Nonaka, S. Udaka, and Y. Yamamoto, Chem. Senses, 2008, 33, 57.

28. B. Morris, and A. Sadana, Sens. Actuators, B, 2005, 106, 498.

29. H. L. Monaco, The EMBO Journal, 1997, 16, 1475.

30. S. T. Jones, Z. Walsh-Korb, S. J. Barrow, S. L. Henderson, J. del Barrio, and O. A. Scherman, ACS Nano, 2016, 10, 3158.

31. S. Kwan and M. Marić, Polymer, 2016, 86, 69.

32. R. Iwai, S. Kusakabe, Y. Nemoto, and Y. Nakayama, Bioconjugate Chem., 2012, 23, 751.

33. Y. Zhang, J. Cai, C. Li, J. Wei, Z. Liu, and W. Xue, J. Mater. Chem. B, 2016, 4, 3733. 